\title{
Computed Tomography Angiography of Type III Takayasu Arteritis
}

EHAB A. ABDEL-GAWAD, MD, University of Virginia Health System, Department of Radiology, Charlottesville, Virginia, USA, and El Minya University, Department of Radiology, El Minya, Egypt; AHMED M. HOUSSEINI, MD; ISMAEEL M. MAGED, MD, University of Virginia Health System, Department of Radiology; and Suez Canal University, Department of Radiology, Ismailia, Egypt; UGUR BOZLAR, MD, University of Virginia Health System, Department of Radiology; and Gulhane Military Medical Academy, Etlik, Ankara, Turkey; PATRICK T. NORTON, MD; KLAUS D. HAGSPIEL, MD, University of Virginia Health System, Department of Radiology, Box 800170, Lee Street, Charlottesville, VA 22908 , USA. Address reprint requests to Prof. Hagspiel. E-mail: kdh2n@ virginia.edu. J Rheumatol 2009;36:652-3; doi:10.3899/jrheum.08858

A 24-year-old woman presented with severe bilateral buttock and lower extremity claudication that had developed over the course of 1 year. Prior to the onset of symptoms she was asymptomatic. Her medical history was remarkable for surgically repaired tetralogy of Fallot. Arm brachial indices were 0.57 on the right and 0.63 on the left. Doppler study showed monophasic waveforms at the thigh level bilateral- ly. Laboratory studies were positive for an elevated erythrocyte sedimentation rate (ESR) of $30 \mathrm{~mm} / \mathrm{h}$ (normal $0-20$ $\mathrm{mm} / \mathrm{h}$ ), but otherwise normal.

A 64-slice multidetector computed tomography angiography was performed and showed severe irregular narrowing of the descending thoracic and abdominal aorta (Figure 1 , arrows). Additionally, there were ostial stenoses of the

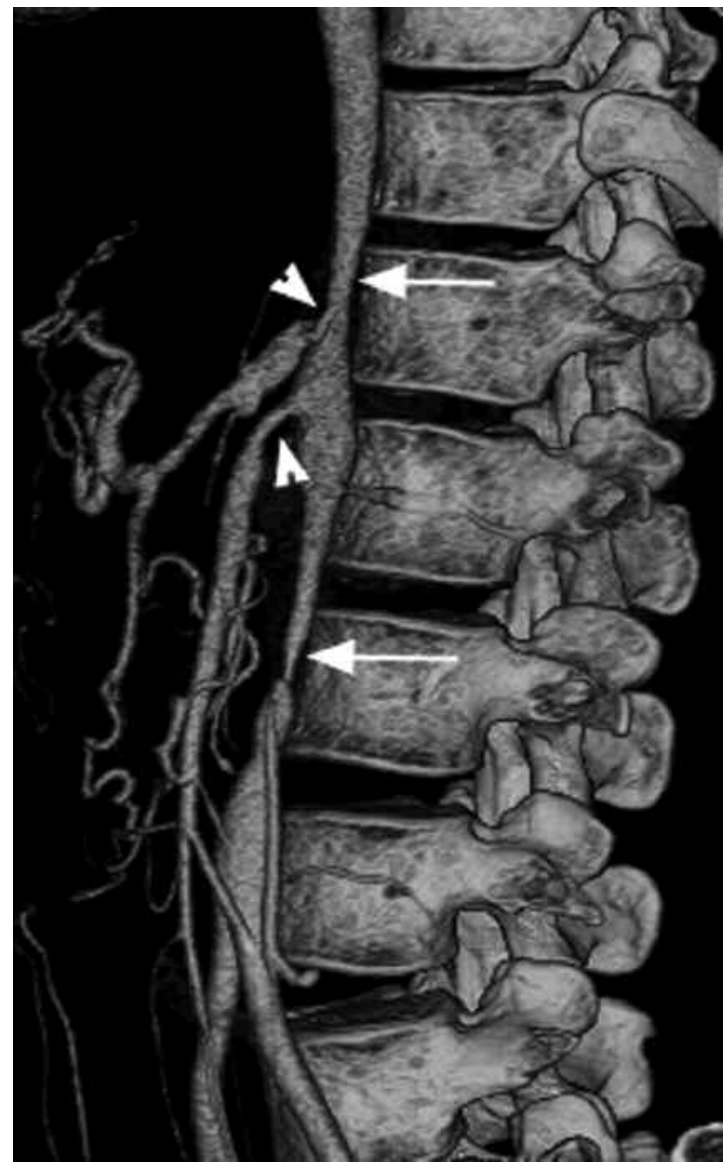

Figure 1. Volume-rendered image of computed tomography angiography (CTA) in left anterior oblique projection shows the high-grade stenosis of the supra and infrarenal abdominal aorta (arrows) as well as ostial stenoses of the superior mesenteric and celiac arteries (arrowheads).

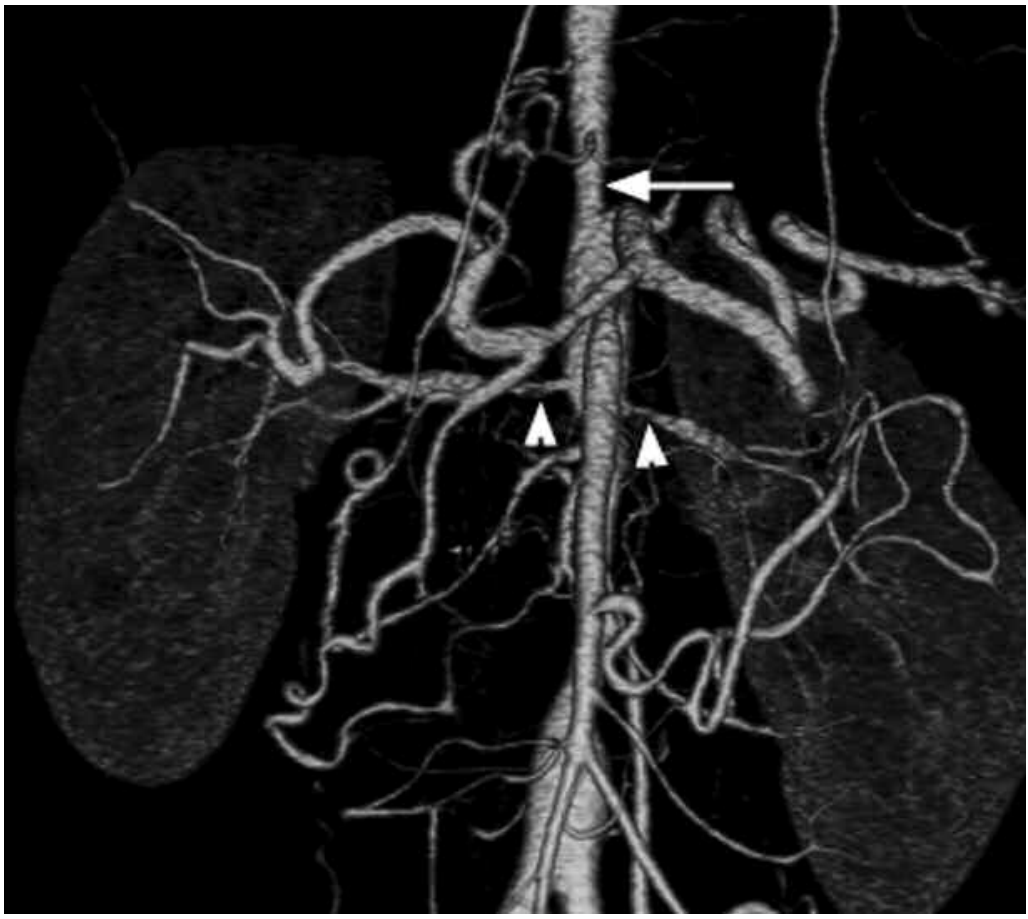

Figure 2. Volume-rendered image of CTA in anterior-posterior projection after removal of the bones shows the irregular and stenotic distal thoracic aorta (arrow). There are also bilateral ostial renal artery stenoses (arrowheads). 


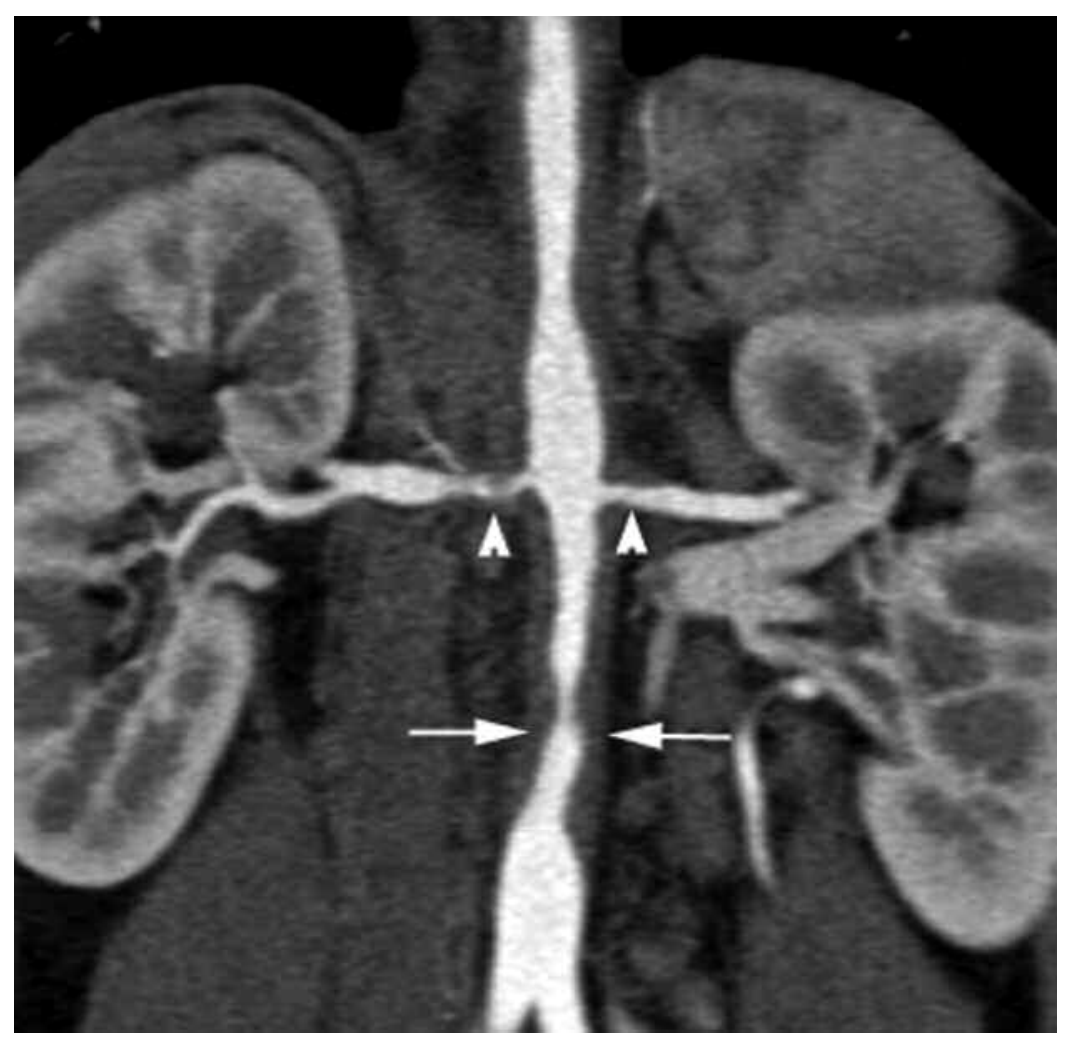

Figure 3. Curved multiplanar reformatted image shows the irregular thickening of the aortic wall (arrows) causing the luminal narrowing of both renal arteries (arrowheads).

visceral branches (Figure 1, arrowheads) and both renal arteries (Figure 2, arrowheads). These luminal changes were caused by pathological and irregular thickening of the aortic wall (Figure 3, arrows) typical for a vasculitis.

Takayasu arteritis (TA) is a large-vessel vasculitis with a possible autoimmune origin that may cause stenosis of the aorta and its major branches ${ }^{1}$. TA commonly presents in the second or third decade of life and affects mainly women; manifestations depend on the location and severity, and range from asymptomatic to severe neurological and vascular pathology2. TA is characterized by granulomatous inflammation of the arterial wall, with marked intimal proliferation and fibrosis of the media and adventitia, which eventually leads to stenosis, occlusion, and occasionally poststenotic dilatation and aneurysm formation. The lesions tend to be segmental with a patchy distribution ${ }^{3}$.

Depending on anatomical distribution, 6 subtypes exist. Type III (our case) is characterized by concomitant involve- ment of the descending thoracic aorta, the abdominal aorta, and/or the renal and visceral arteries. The ascending aorta and the aortic arch and its branches are spared ${ }^{1}$.

Symptomatic improvement occurred after steroid treatment in our patient, and can be expected together with resolution of the active inflammatory process if initiated early ${ }^{4}$.

\section{REFERENCES}

1. Marcio V, Luciana PS, Ronaldo H, Roberto B, Luis F, Claudia C. Gadolinium-enhanced three-dimensional MR angiography of Takayasu arteritis. RadioGraphics 2004;24:773-86.

2. Hartman JM, Bekkers JA, Roos-Hesselink JW, Bogers AJ. Underestimated abdominal vascular pathology in a patient with Takayasu arteritis. Interact Cardiovasc Thorac Surg 2006;5:451-3.

3. Moriwaki R, Noda M, Yajima M, Sharma BK, Numano F. Clinical manifestations of Takayasu arteritis in India and Japan: new classification of angiographic findings. Angiology 1997;48:369-79.

4. de Franciscis S, Serra R, Luongo A, Sabino G, Puzziello A. The management of Takayasu's arteritis: personal experience. Ann Vasc Surg 2007;21:754-60. 